\title{
Characterization of Leishmania Species Isolated from Cutaneous Human Samples from Central Region of Syria by RFLP Analysis
}

\author{
Samar Anis Al-Nahhas ${ }^{1}$ and Rania Magdy Kaldas ${ }^{2}$ \\ ${ }^{1}$ Department of Animal Biology, Faculty of Science, Damascus University, Damascus 96311, Syria \\ ${ }^{2}$ Vector Biology Research Program, United States Naval Medical Research Unit No. 3 (NAMRU-3), Cairo 11517, Egypt \\ Correspondence should be addressed to Samar Anis Al-Nahhas; samarnahas@yahoo.com
}

Received 25 June 2013; Accepted 13 August 2013

Academic Editors: L. Nimri, O. F. Osman, J. M. Perez, and G. Swedberg

Copyright (C) 2013 S. A. Al-Nahhas and R. M. Kaldas. This is an open access article distributed under the Creative Commons Attribution License, which permits unrestricted use, distribution, and reproduction in any medium, provided the original work is properly cited.

\begin{abstract}
Cutaneous leishmaniasis (CL) is an endemic disease and a public health problem in Hama governorate located in the central region of Syria. The aim of this study was to characterize Leishmania species isolated from human skin samples. A polymerase chain reaction, restriction fragment length polymorphism (PCR-RFLP) assay, was performed on skin lesion material samples from 32 patients with confirmed CL by direct microscopic examination in order to prove its usefulness and efficiency for identification of Leishmania species. Leishmania tropica (L. tropica) is confirmed as an etiologic agent of CL in this area.
\end{abstract}

\section{Introduction}

Leishmaniasis is a parasitic endemic disease that spreads over the world in tropical and subtropical regions. Cutaneous leishmaniasis (CL) is currently endemic in 87 countries worldwide (20 countries in the new world and 67 countries in the old world), with an estimation of new infected cases from 500,000 to one million annually [1].

In Syria, CL has two forms: zoonotic cutaneous leishmaniasis (ZCL) caused by L. major and anthroponotic cutaneous leishmaniasis (ACL) caused by L. tropica [2-4]. During the last decade, CL represented a major public health problem in Syria, because the incidence of CL has increased significantly. According to the Syrian Ministry of Health, Department of Infectious Diseases, the reported number of cutaneous leishmaniasis was 12,832 cases in 1999, and this number reached 46,148 cases in 2009. An average of $24 \%$ of the reported cases in Syria originated from the middle region (Hama, Idleb, and Homs governorates).

Traditionally, diagnosis of leishmaniasis in Syria relies on the clinical manifestations of the disease with the detection of the intracellular stages of the parasite by direct examination of smears or biopsies of skin lesions and culturing of specimens $[5,6]$.

However, the Leishmania species identification is not possible using these methods because all Leishmania parasites are morphologically similar. Actually, isoenzyme analysis is the golden method for identification of Leishmania species and subspecies. However, this procedure is time consuming, culture dependent and requires considerable expertise [7-11].

Therefore, accurate diagnosis of cutaneous leishmaniasis, treatment, disease prevention, and controlling strategies, as well as management decisions, require identification of the causative species of Leishmania parasite [10-12]. In the last decade, several PCR assays for detection and differentiation of parasites, including species-specific PCR, single-strand conformation polymorphisms (SSCP), and restriction fragment length polymorphism (RFLP) analysis, proved to be sensitive and powerful tools for direct detection of Leishmania in clinical samples as well as for parasite characterization [12-14]. A universal PCR method targeting the internal transcribed spacer-1 (ITS1) region lying between 


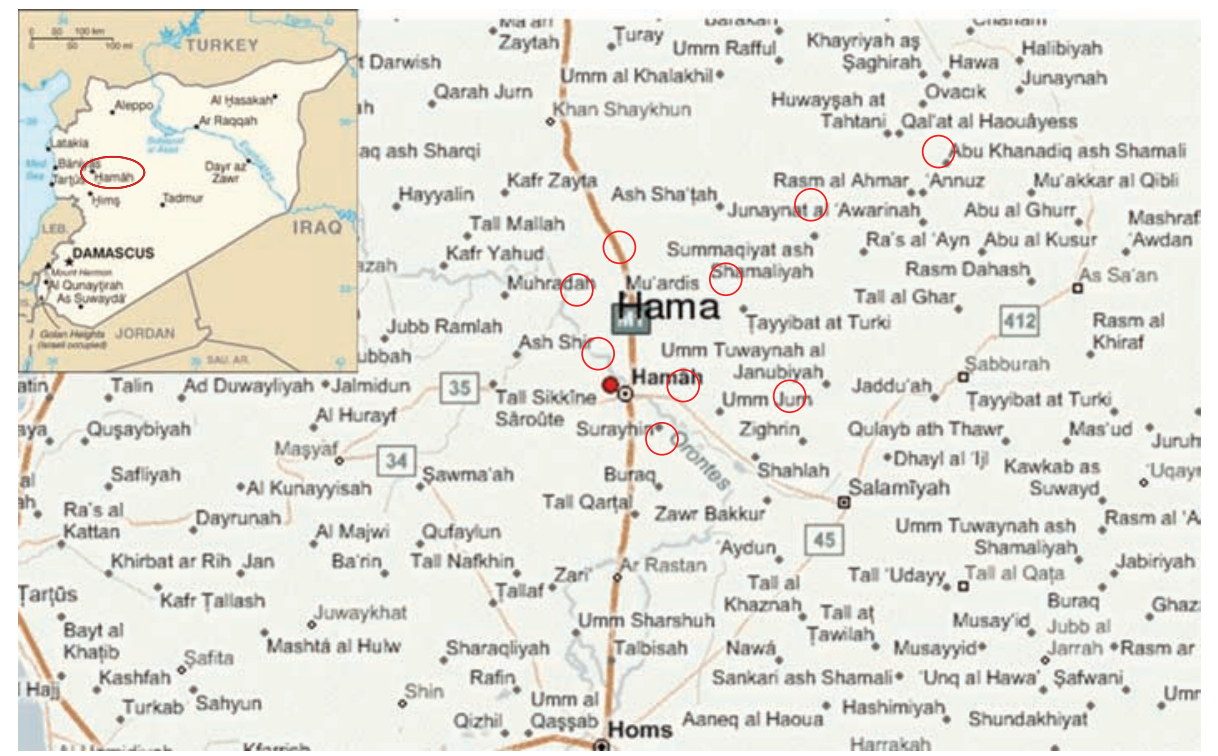

FIGURE 1: Map showing the areas (circle) in Hama governorate where cutaneous leishmaniasis samples were collected.

the genes coding for 18S rRNA and 5.8S rRNA proved to be useful for direct diagnosis and identification of Leishmania parasite, due to its high conservation among species [11, 15-19]. ITS1-PCR and RFLP can be used for direct species identification of Leishmania in patient tissues, blood, or other samples preventing the use of microscopic examination and cultivation $[15,16,18-20]$.

In this study, we aimed to identify the Leishmania species that caused cutaneous leishmaniasis in Hama governorate, middle region of Syria.

\section{Materials and Methods}

2.1. Samples. A total of 32 samples were collected (between December 2009 and January 2010) from individuals presented to the local sanitary (Leishmania) centers for consultation and treatment in Hama, suffering from skin lesions for more than 3 weeks (Figure 1).

Simple direct questionnaire about clinical and epidemiological information (including age, gender, clinical symptoms, animals, and insects presence) was filled out for each patient. The patients were notified of all the procedures to take place, and a signed informed consent was given to each. The ethics committee of the Ministry of Health, Damascus, Syria, approved this study. After cleaning the lesion, aspirate of skin lesion was smeared, fixed (using methanol), stained (using Giemsa), and examined microscopically for the presence of Leishmania amastigotes.

2.2. DNA Extraction. Total DNA was extracted from human lesion smear samples using the Qiagen DNA Mini Kit (Qiagen, Valencia, CA), as per tissue protocol instructions, and eluted in $200 \mu \mathrm{L}$ elution buffer. DNA extracts were stored at $-20^{\circ} \mathrm{C}$ until being used.
2.3. PCR Amplification. The internal transcribed region (ITS1) of the small subunit ribosomal DNA was amplified from samples by conventional PCR using the primers L5.8S: $5^{\prime}$-TGATACCACTTATCGCACTT- ${ }^{\prime}$ and LITSR: $5^{\prime}$ CTGGATCATTTTCCGATG-3'; ; 21$]$.

Amplification reactions were performed in volumes of $50 \mu \mathrm{L}$. All PCR assays were optimized with regard to annealing temperature, to concentrations of primers, and to cycling protocols. For all experiments, five $\mu \mathrm{L}$ of isolated DNA was added to the PCR mixture (the mixture contained Go Taq Flexi DNA Polymerase "Promega, USA": $10 \mu \mathrm{L}$ Green Go Taq Flexi DNA Polymerase, $3 \mathrm{U}$ Go Taq DNA polymerase, $200 \mu \mathrm{L}$ dNTPs, $4.0 \mathrm{mM} \mathrm{MgCl}_{2}$, and $30 \mu \mathrm{m}$ each primer "Sigma: Genosys Corp., USA"), and each individual PCR experiment included at least one positive control: L. tropica MHOM/TR/05/EP119; L. major IPAP/EG89/SI-177 and $L$. infantum EP 50 ( $5 \mu \mathrm{L}$ of DNA of reference strain) and one negative control ( $5 \mu \mathrm{L}$ of nuclease-free water). The cycling conditions were $\left(94^{\circ}, 30 \mathrm{sec} ; 53^{\circ}, 1 \mathrm{~min} ; 72^{\circ}, 1 \mathrm{~min}\right)$ repeated for 37 cycles. Amplification products were subjected to electrophoresis in $2 \%$ agarose (Sigma-Aldrich, St. Louis, MO) at $100 \mathrm{~V}$ in $1 \mathrm{x}$ TAE ( $40 \mathrm{mM}$ Tris-acetate, $1 \mathrm{mM}$ EDTA, $\mathrm{pH}$ 8.3) buffer, stained with ethidium bromide $(5 \mu \mathrm{L} / 100 \mathrm{~mL})$, and visualized and photographed using a UV transilluminator.

2.4. RFLP Analysis of Amplified ITS1. Restriction fragment length polymorphism (RFLP) analysis of the ITS1 amplicons was performed on the ITS1 amplicons, obtained from 32 smear samples and the reference strain, using the restriction enzyme HaeIII $(1 \mu \mathrm{L})$ (Promega, USA) without prior purification. The digested fragments were subjected to electrophoresis in 2\% agarose (Sigma-Aldrich, St. Louis, MO) at $100 \mathrm{~V}$ in $1 \mathrm{x}$ TAE buffer, stained with ethidium bromide $(5 \mu \mathrm{L} / 100 \mathrm{~mL})$, and visualized and photographed using a UV transilluminator. 


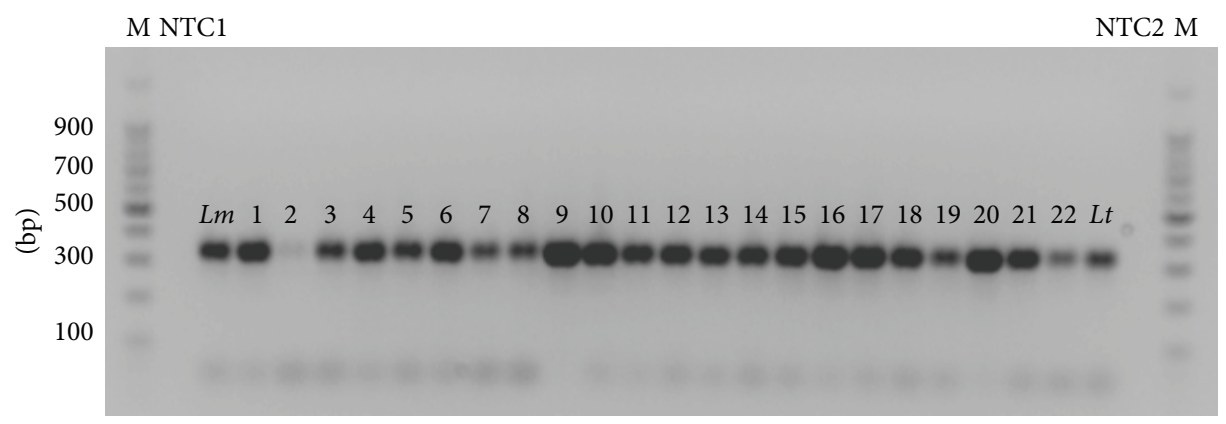

FIGURE 2: Agarose gel electrophoresis results of ITS1-PCR from Giemsa-stained human smears. M: molecular marker (100 bp); Lanes 122: samples; Lm: L. major (IPAP/EG89/SI-177); Lt: L. tropica (MHOM/TR/05/EP119) positive control; NTC1, NTC2: negative control for contamination detection.

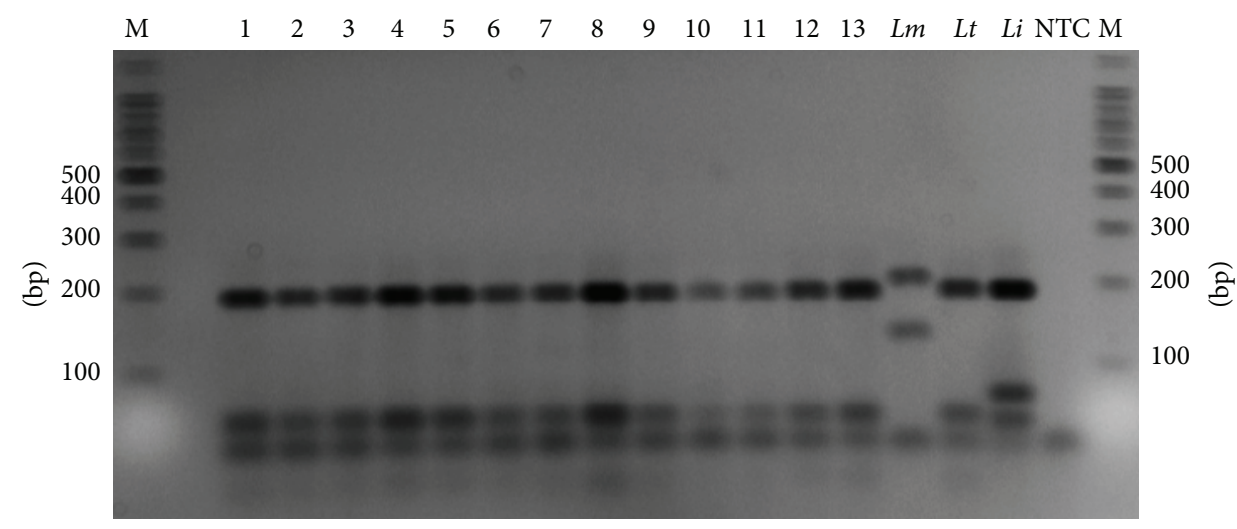

FIGURE 3: Restriction fragment length polymorphism (RFLP) analysis of ITS1-PCR fragments amplified from samples and standard isolates DNA, by using HaeIII. M: molecular marker (100 bp); Lanes 1-13: samples; Lm: Leishmania major (IPAP/EG89/SI-177); Lt: Leishmania tropica (MHOM/TR/05/EP119); Li: Leishmania infantum EP50; NTC: non template control.

\section{Results}

3.1. Characteristics of Patients with Suspected CL. Of the 32 CL cases, 18 (56.3\%) were males and 14 (43.8\%) were females. The patients were in the age range from 2 to 70 years. None of the examined patients had been out of Hama governorate during the 6 months preceding the onset of lesions, suggesting that these cases are autochthonous. The lesions were mainly located on the upper extremities $(67.5 \%)$ compared with $25.9 \%$ on the facial region and $6.5 \%$ on the legs, typical exposed fly bites areas. Most of these patients had more than one lesion (average 1-4 lesions). All patients had localized and typical lesion of CL, from crusted nodule to ulcerated lesions. The lesions diameter varied from 0.2 to $3 \mathrm{~cm}$, and the duration lesion appearance varied from 15 days to 4 months.

3.2. Leishmania Species Identity. 32 samples (100\%) were positive for the presence of Leishmania, by ITS1-PCR. The undigested ITS1 amplicons produced a band of expected size depending on whether Leishmania species (300-350 bp), when examined by $2 \%$ Agarose gel electrophoresis (Figure 2).

The ITS1-PCR was further identified by digestion with the restriction enzyme HaeIII. However, RFLP patterns for 32 positive samples analyzed presented restriction bands
60 and 200 bp (Figure 3) which are correlated to L. tropica (MHOM/TR/05/EP119) reference strain (positive control) pattern.

\section{Discussion}

The diagnosis of leishmaniasis in Syria is mostly based on clinical features and direct observation of the amastigotes stage in clinical materials [5, 6]. Many previous studies mentioned that the conventional methods are not able to differentiate between Leishmania species due to their homogeneous morphologies [14, 22, 23]. Therefore, it was necessary to apply a sensitive method helping in diagnosis, differentiate between different Leishmania species, and improve therapy procedure.

This study focused on diagnosis and species identification of 32 samples obtained from patients with CL in Hama governorate in Syria. We used specific primers [21] that amplify a 300-350 bp fragment in the ribosomal internal transcribed spacer-1 (region that separates the ssu rRNA and 5.8S rRNA genes and varies between Leishmania species) from different samples onto glass slides. The ITS1 fragments which are similar to those obtained with Leishmania standard strains [15-17, 21, 24], were chosen as a target for diagnostic PCR analysis [16]. Many studies mentioned the important 
role of the restriction enzymes in the identification of all medically relevant Leishmania parasites [11, 16, 25]. As result of digestion with HaeIII, ITS1-PCR amplicon yielded 60 and $200 \mathrm{bp}$ fragments which are corresponding with $L$. tropica patterns $[15,16,24,26]$. It was confirmed that CL infections in all patients from Hama governorate were caused by $L$. tropica.

In conclusion, ITS1-PCR followed by RFLP can be considered the method of chance for diagnosing and identifying the causative species of cutaneous leishmaniasis, in Syria, for accuracy treatment.

\section{Acknowledgments}

The authors thank their clinical colleagues for providing them with the patient samples and clinical types. The authors are also very grateful to Dr. Jeffrey T. Villinski (Vector Biology Research Program at the United States Naval Medical Research Unit No. 3) for his advice and help. This study was funded by the first author. Practical collaboration with United States Naval Medical Research Unit No. 3 (NAMRU-3) was funded by GEIS CORE Grant no. C0303_10_N3.

\section{References}

[1] World Health Organization (WHO), Manual For Case Management of Cutaneous Leishmaniasis in the WHO, Eastern Mediterranean Region, 2012.

[2] A. Khiami, J. Dereure, F. Pratlong, A. Martini, and J. Rioux, "La leishmaniose cutanee humaine a Leishmania major mon26 Aux environs de Damas (Syrie)," Le Bulletin de la Société de Pathologie Exotique, vol. 84, pp. 1-5, 1991.

[3] K. Knio, E. Baydoun, R. Tawk, and N. Nuwayri-Salti, "Isoenzyme characterization of Leishmania isolates from Lebanon and Syria," American Journal of Tropical Medicine and Hygiene, vol. 63, no. 1-2, pp. 43-47, 2000.

[4] J. A. Rioux, R. W. Ashford, and A. Khiami, "Ecoepidemiology of leishmaniases in Syria. 3. Leishmania major infection in Psammomys obesus provides clues to life history of the rodent and possible control measures," Annales de Parasitologie Humaine et Comparee, vol. 67, no. 6, pp. 163-165, 1992.

[5] A. Tayeh, L. Jalouk, and S. Cairncross, "Twenty years of cutaneous leishmaniasis in Aleppo, Syria," Transactions of the Royal Society of Tropical Medicine and Hygiene, vol. 91, no. 6, pp. 657-659, 1997.

[6] S. A. Al-Nahhas, "Serodiagnosis of cutaneous leishmaniasis in the Syrian Arab Republic," Saudi Medical Journal, vol. 30, no. 3, pp. 382-386, 2009.

[7] J. A. Rioux, G. Lanotte, E. Serres, F. Pratlong, P. Bastien, and J. Perieres, "Taxonomy of Leishmania. Use of isoenzymes. Suggestions for a new classification," Annales de Parasitologie Humaine et Comparee, vol. 65, no. 3, pp. 111-125, 1990.

[8] M. Belkaïd, Z. Harrat, B. Hemrioui, M. Thellier, A. Datry, and M. Danis, "A propos d'un milieu simple pour l'isolement et la culture des leishmanies," Le Bulletin de la Société de Pathologie Exotique, vol. 89, pp. 276-277, 1996.

[9] K. Aoun, A. Bouratbine, Z. Harrat et al., "Epidemiological and parasitological data for sporadic cutaneous leishmaniasis in northern Tunisia," Bulletin de la Societe de Pathologie Exotique, vol. 93, no. 2, pp. 101-103, 2000.
[10] G. Wortmann, L. Hochberg, H.-H. Houng et al., "Rapid identification of Leishmania complexes by a real-time PCR assay," American Journal of Tropical Medicine and Hygiene, vol. 73, no. 6, pp. 999-1004, 2005.

[11] I. B. Abda, F. De Monbrison, N. Bousslimi, K. Aoun, A. Bouratbine, and S. Picot, "Advantages and limits of real-time PCR assay and PCR-restriction fragment length polymorphism for the identification of cutaneous Leishmania species in Tunisia," Transactions of the Royal Society of Tropical Medicine and Hygiene, vol. 105, no. 1, pp. 17-22, 2011.

[12] M. Jirkù, E. Zemanov, A. Al-Jawabreh, G. Schonian, and J. Lukes, "Development of a direct species-specific PCR assay for differential diagnosis of Leishmania tropica," Diagnostic Microbiology and Infectious Disease, vol. 55, pp. 75-79, 2006.

[13] G. Spanakos, E.-T. Piperaki, P. G. Menounos, N. Tegos, A. Flemetakis, and N. C. Vakalis, "Detection and species identification of Old World Leishmania in clinical samples using a PCRbased method," Transactions of the Royal Society of Tropical Medicine and Hygiene, vol. 102, no. 1, pp. 46-53, 2008.

[14] J. Marfurt, A. Nasereddin, I. Niederwieser, C. L. Jaffe, H.-P. Beck, and I. Felger, "Identification and differentiation of Leishmania species in clinical samples by PCR amplification of the miniexon sequence and subsequent restriction fragment length polymorphism analysis," Journal of Clinical Microbiology, vol. 41, no. 7, pp. 3147-3153, 2003.

[15] G. Schönian, L. Schnur, M. El Fari et al., "Genetic heterogeneity in the species Leishmania tropica revealed by different PCRbased methods," Transactions of the Royal Society of Tropical Medicine and Hygiene, vol. 95, no. 2, pp. 217-224, 2001.

[16] G. Schönian, A. Nasereddin, N. Dinse et al., "PCR diagnosis and characterization of Leishmania in local and imported clinical samples," Diagnostic Microbiology and Infectious Disease, vol. 47, no. 1, pp. 349-358, 2003.

[17] A. Al-Jawabreh, G. Schoenian, O. Hamarsheh, and W. Presber, "Clinical diagnosis of cutaneous leishmaniasis: a comparison study between standardized graded direct microscopy and ITS1-PCR of Giemsa-stained smears," Acta Tropica, vol. 99, no. 1, pp. 55-61, 2006.

[18] A. M. R. Davila and H. Momen, "Internal-transcribed-spacer (ITS) sequences used to explore phylogenetic relationships within Leishmania," Annals of Tropical Medicine and Parasitology, vol. 94, no. 6, pp. 651-654, 2000.

[19] E. Bensoussan, A. Nasereddin, F. Jonas, L. F. Schnur, and C. L. Jaffe, "Comparison of PCR assays for diagnosis of cutaneous leishmaniasis," Journal of Clinical Microbiology, vol. 44, no. 4, pp. 1435-1439, 2006.

[20] S. O. Toz, A. Nasereddin, Y. Ozbel et al., "Leishmaniasis in Turkey: molecular characterization of Leishmania from human and canine clinical samples," Tropical Medicine and International Health, vol. 14, no. 11, pp. 1401-1406, 2009.

[21] N. O. El Tai, O. F. Osman, M. El Fari, W. Presber, and G. Schönian, "Genetic heterogeneity of ribosomal internal transcribed spacer in clinical samples of Leishmania donovani spotted on filter paper as revealed by single-strand conformation polymorphisms and sequencing," Transactions of the Royal Society of Tropical Medicine and Hygiene, vol. 94, no. 5, pp. 575579, 2000.

[22] F. Akkafa, F. Dilmec, and Z. Alpua, "Identification of Leishmania parasites in clinical samples obtained from cutaneous leishmaniasis patients using PCR-RFLP technique in endemic region, Sanliurfa province, in Turkey," Parasitology Research, vol. 103, no. 3, pp. 583-586, 2008. 
[23] M. L. Khatri, T. Di Muccio, and M. Gramiccia, "Cutaneous leishmaniasis in North-Western Yemen: a clinicoepidemiologic study and Leishmania species identification by polymerase chain reaction-restriction fragment length polymorphism analysis," Journal of the American Academy of Dermatology, vol. 61, no. 4, pp. e15-e21, 2009.

[24] M. Doudi, S. H. Hejazi, M. R. Razavi, M. Narimani, S. Khanjani, and G. Eslami, "Comparative molecular epidemiology of Leishmania major and Leishmania tropica by PCR-RFLP technique in hyper endemic cities of Isfahan and Bam, Iran," Medical Science Monitor, vol. 16, no. 11, pp. 530-535, 2010.

[25] J. H. Roelfsema, N. Nozari, T. Herremans, L. M. Kortbeek, and E. Pinelli, "Evaluation and improvement of two PCR targets in molecular typing of clinical samples of Leishmania patients," Experimental Parasitology, vol. 127, no. 1, pp. 36-41, 2011.

[26] B. Rotureau, C. Ravel, P. Couppié et al., "Use of PCR-restriction fragment length polymorphism analysis to identify the main new world Leishmania species and analyze their taxonomic properties and polymorphism by application of the assay to clinical samples," Journal of Clinical Microbiology, vol. 44, no. 2, pp. 459-467, 2006. 

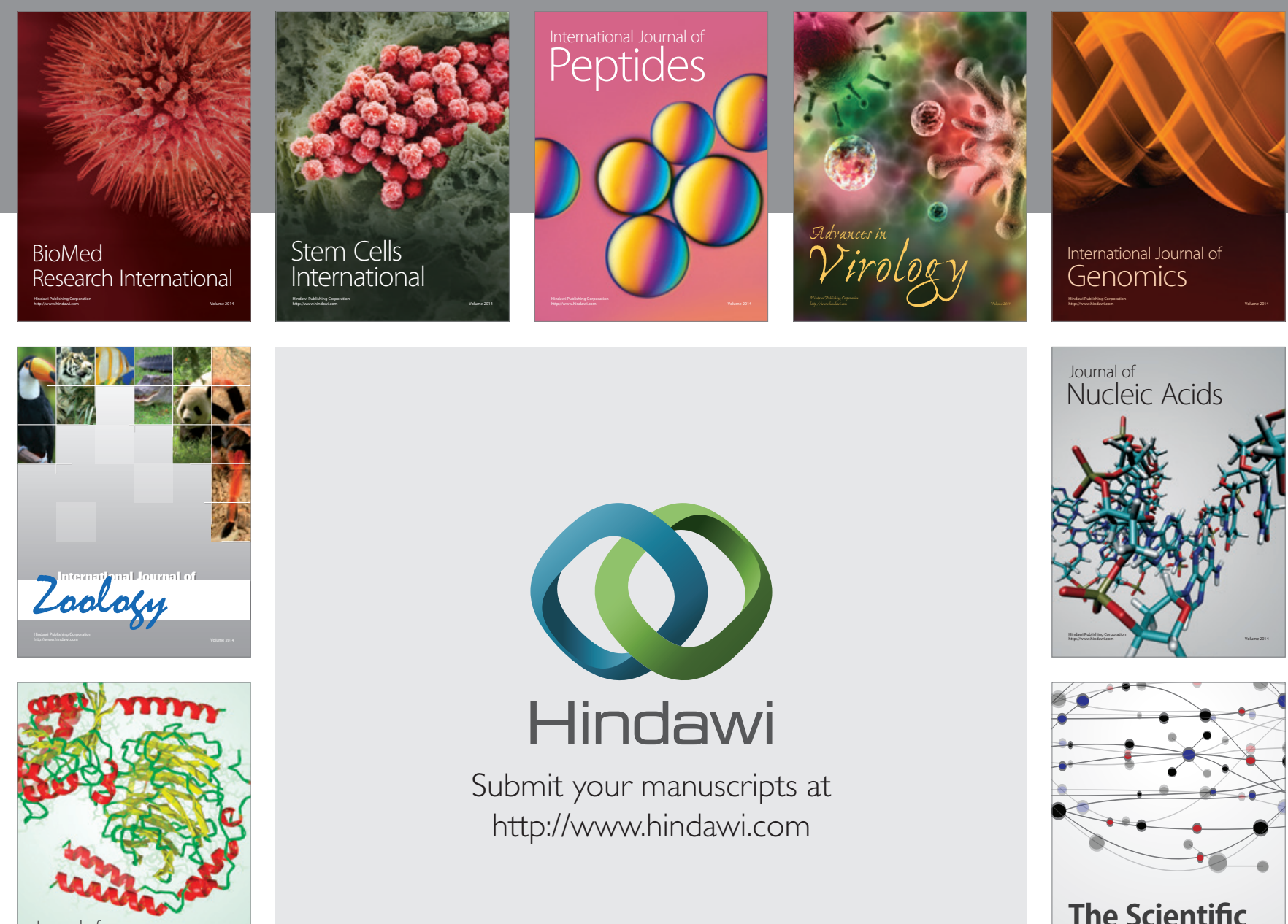

Submit your manuscripts at

http://www.hindawi.com

Journal of
Signal Transduction
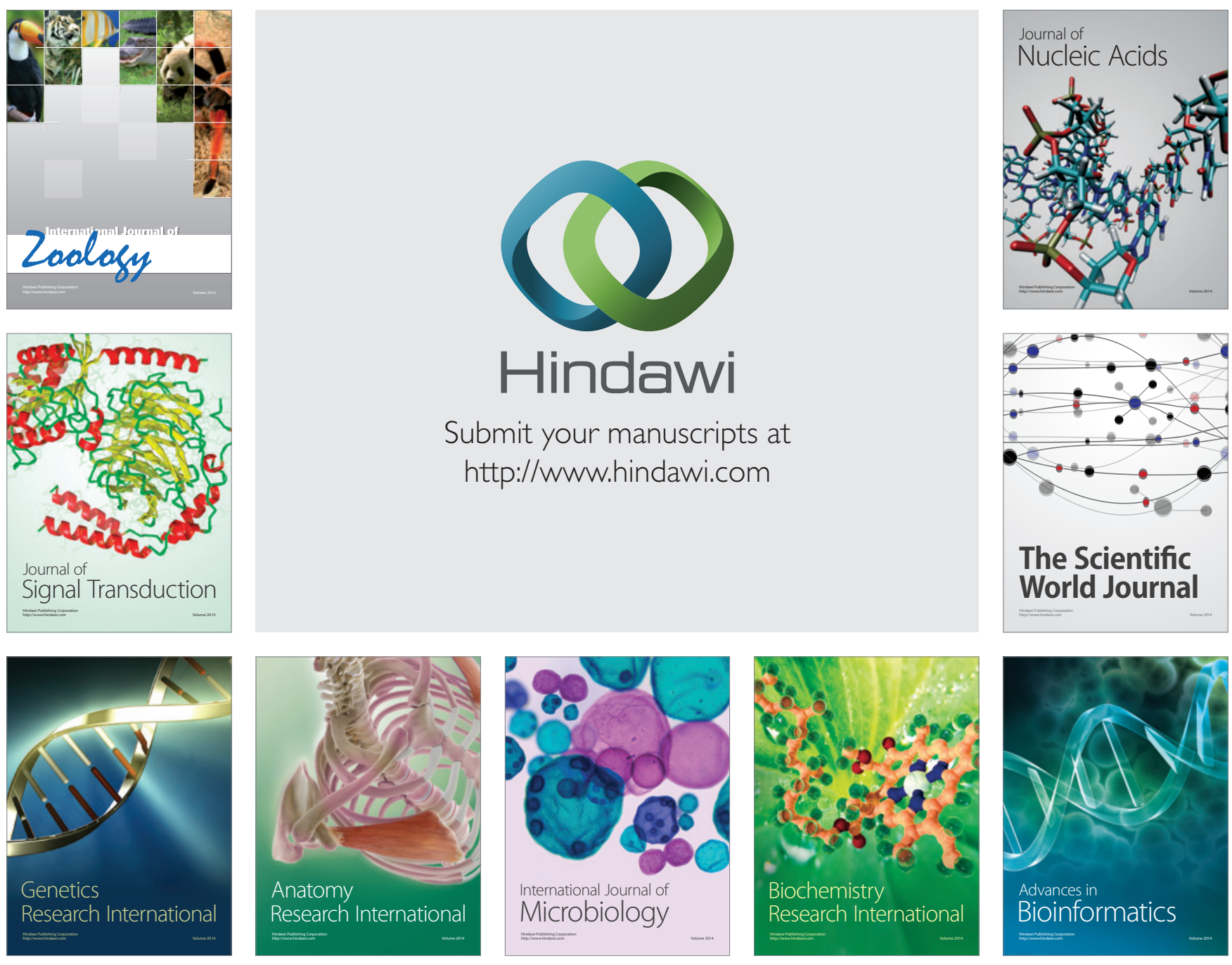

The Scientific World Journal
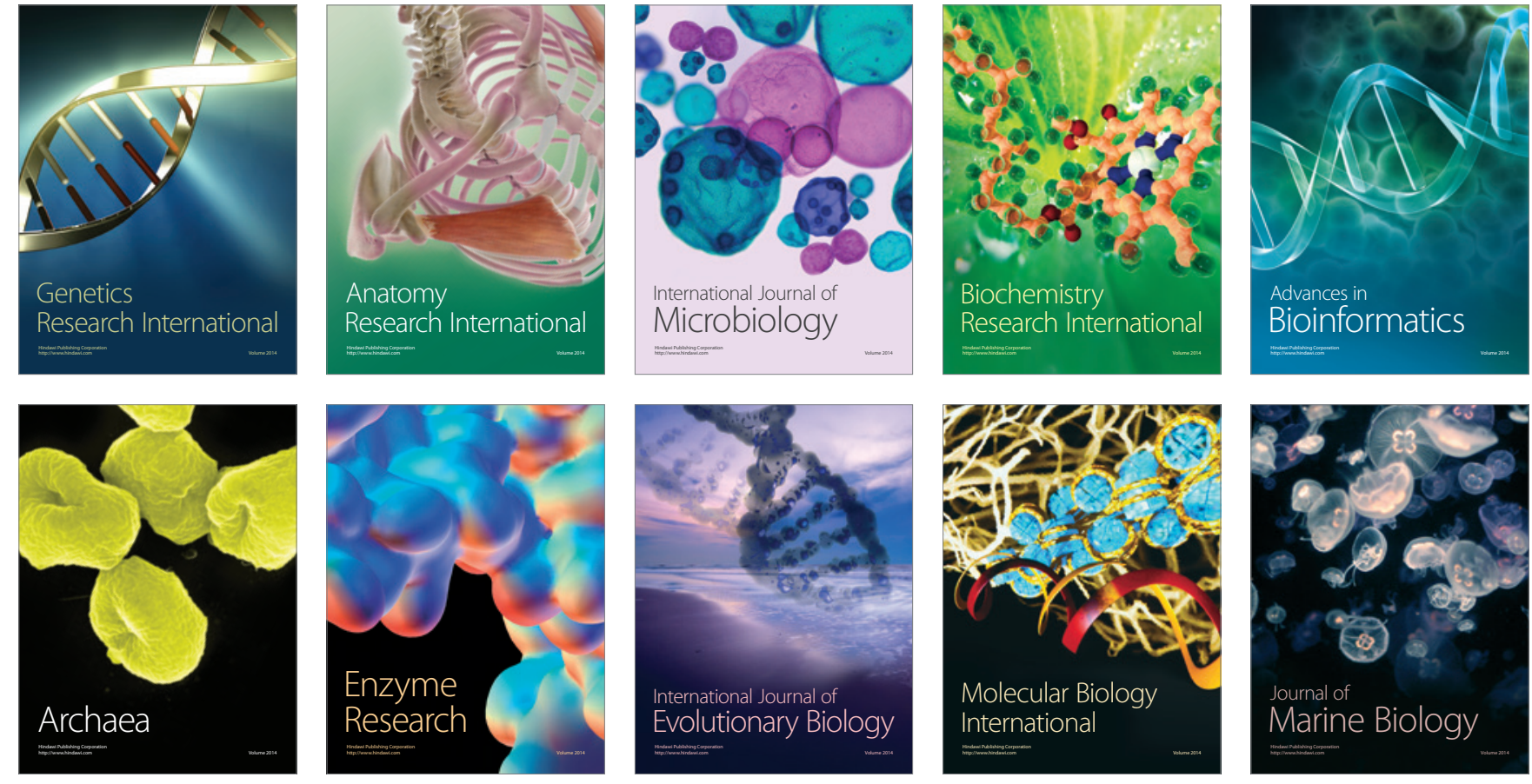